\title{
Spontaneous retroclival hematoma in pituitary apoplexy: case series
}

\author{
Avetis Azizyan, MD, ${ }^{1}$ Joseph M. Miller, MD, MS, ${ }^{1}$ Ramzi I. Azzam, MD, PhD, ${ }^{1}$ Marcel M. Maya, MD, ${ }^{1}$ \\ Pouyan Famini, MD, ${ }^{2}$ Barry D. Pressman, MD, ${ }^{1}$ and Franklin G. Moser, MD, MMM${ }^{1}$ \\ Departments of ${ }^{1}$ Imaging and ${ }^{2}$ Medicine, Cedars-Sinai Medical Center, Los Angeles, California
}

OBJECT Pituitary apoplexy is a rare and potentially life-threatening disorder that is most commonly characterized by a combination of sudden headache, visual disturbance, and hypothalamic/hormonal dysfunction. In many cases, there is hemorrhagic infarction of an underlying pituitary adenoma. The resulting clinical symptoms are due to compression of the remaining pituitary, cavernous sinuses, or cranial nerves. However, there are only 2 case reports in the literature describing spontaneous retroclival expansion of hemorrhage secondary to pituitary apoplexy. Ten cases of this entity with a review of the literature are presented here.

METHODS This is a single-institution retrospective review of 2598 patients with sellar and parasellar masses during the 10-year period between 1999 and 2009. The pituitary and brain MRI and MRI studies were reviewed by 2 neuroradiologists for evidence of apoplexy, with particular attention given to retroclival extension.

RESULTS Eighteen patients (13 men and 5 women; mean age 54 years) were identified with presenting symptoms of sudden onset of headache and ophthalmoplegia, and laboratory findings consistent with pituitary apoplexy. Ten of these patients ( 8 men and 2 women; mean age 55 years) had imaging findings consistent with retroclival hematoma.

CONCLUSIONS Retroclival hemorrhage was seen in the majority of cases of pituitary apoplexy (56\%), suggesting that it is more common than previously thought.

http://thejns.org/doi/abs/10.3171/2014.12.JNS14445

KEY WORDS pituitary surgery; apoplexy; retroclival; hemorrhage; hematoma

$\mathrm{P}$ ITUITARY apoplexy is a complex clinical entity that is typically characterized by the acute onset of headache, visual disturbance, and subsequent hormonal dysfunction secondary to disruption of the hypothalamicpituitary axis. The diagnosis is primarily based on abnormal MR or CT imaging findings with clinical and laboratory evidence reflecting hormonal disturbance. Suprasellar extension of the enlarged gland can affect the optic chiasm, cavernous sinus, and cranial nerves. However, retroclival extension of the hemorrhage beyond the pituitary is unusual and is not typically considered in the imaging evaluation. To the best of our knowledge, spontaneous retroclival expansion of hemorrhage secondary to pituitary apoplexy has only been reported twice in the literature. This clinical report describes 18 patients with pituitary apoplexy, of whom 10 had retroclival hematoma.

\section{Methods}

This is a single-institution review of over 10,000 brain imaging studies performed between 1999 and 2009 utilizing CT or MRI, which identified 2598 patients with sellar and parasellar masses. ${ }^{6}$ Eighteen patients $(13$ men and 5 women; mean age 54 years) were identified with the presenting symptoms of sudden onset of headache and ophthalmoplegia and laboratory findings consistent with pituitary apoplexy. Ten of these patients ( 8 men and 2 women; mean age 55 years) had imaging findings consistent with retroclival hematoma. Of these 10 patients, 6 patients underwent follow-up imaging after resolution of their acute symptoms.

The primary clinical information was obtained via retrospective chart review, which revealed a wide range of

SUBMITTED February 28, 2014. ACCEPTED December 9, 2014.

INCLUDE WHEN CITING Published online July 3, 2015; DOI: 10.3171/2014.12.JNS14445.

DISCLOSURE The authors report no financial interests or conflicts related to this study. There are no sources of funding to report. 
ages (23-82 years) and included patients with no prior medical history as well as patients with complex medical problems. Only 1 of the 10 patients who developed a retroclival hematoma had a prior diagnosis of a pituitary adenoma. The remaining 9 patients presented with apoplexy. Eight of 10 patients received transsphenoidal decompression, with severe or progressing ophthalmoplegia being the primary indicator for neurosurgical intervention. There was no imaging or clinical evidence of mass effect on the posterior fossa contents, such as compression of the basilar artery or deformity of the brainstem. Consequently, retroclival hematoma was not specifically addressed in the patients who underwent surgery.

Due to the extended period of this study, both 1.5-T and 3.0-T MR images were reviewed, and imaging protocols differed slightly with time. However, T1- and T2-weighted sequences, with and without contrast, were available for all patients. Each imaging study was independently reviewed by 2 neuroradiologists (R.I.A. and M.M.M.). All patients underwent MR imaging within 48 hours of clinical symptom onset.

In comparison with the brainstem, retroclival hematoma presented with isointense signals on noncontrastenhanced T1-weighted sequences and heterogeneous enhancement on contrast images. The size and location of the retroclival hematoma was measured in the anteroposterior and craniocaudal dimensions in the sagittal plane on T1-weighted sequences.

\section{Results}

Based on the MR images, hyperintense retroclival lesions were identified in 10 of 18 patients $(56 \%)$ (8 men and 2 women; mean age 55 years) on T1-weighted sequences (Table 1). In all 10 patients, an undulating lesion (various sizes) appeared to extend along the posterior border of the clivus and terminate at the level of the basion. The average size was measured as $3.6 \mathrm{~mm} \times 30.4 \mathrm{~mm}$ in the anteroposterior and craniocaudal dimensions. On T1-weighted sequences, the lesions appeared isointense to the brainstem in all 10 patients $(100 \%)$ (Fig. 1). Contrast enhancement, as defined by a greater than 10-unit increase in T1 signal, was identified in 9 patients $(90 \%)$ (Fig. 1). However, the
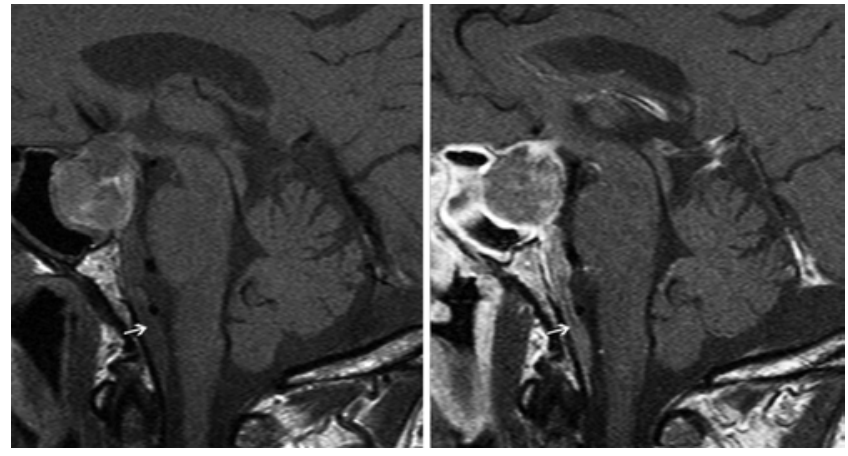

FIG. 1. Sagittal precontrast (left) and postcontrast (right) T1-weighted MRI sequences of the sella turcica in a patient with the clinical symptoms of apoplexy, demonstrating a retroclival enhancing mass (arrows) consistent with hematoma.

degree of enhancement was less than that in the adjacent venous structures, thereby making these lesions unlikely to represent engorgement of the basilar plexus. In 4 patients with T2-weighted sequences, the lesion appeared predominantly hypointense to the brainstem in 3 patients (75\%). No diffusion restriction was seen on the diffusionweighted images and apparent diffusion coefficient maps (Fig. 2).

Follow-up imaging was performed in 6 of 10 patients after the resolution of the acute presenting symptoms. The remaining 4 patients did not undergo additional imaging after initial treatment and were instead followed clinically. There was complete resolution of the retroclival lesion on T1-weighted pre- and postcontrast sequences in 5 patients $(83 \%)$ (Fig. 3). The size of the original hemorrhages varied from subtle to extensive in the 10 patients included in this series (Fig. 4). In many cases, direct extension from the sella turcica can be directly seen.

\section{Discussion}

Retroclival hemorrhage is a very rare imaging finding that most commonly has been described in the setting of trauma. ${ }^{10,13,17,21}$ Rare associations with aneurysm rupture ${ }^{3,11}$ and pituitary apoplexy, 7,14 as well as spontaneous retroclival hemorrhage, ${ }^{5,18,20}$ have been reported. To the best of

TABLE 1. Summary of patients with retroclival imaging findings and the clinical symptoms of pituitary apoplexy

\begin{tabular}{|c|c|c|c|c|c|c|c|c|c|c|}
\hline $\begin{array}{l}\text { Case } \\
\text { No. }\end{array}$ & $\begin{array}{l}\text { Age } \\
\text { (yrs) }\end{array}$ & Sex & $\begin{array}{c}\text { Known } \\
\text { Adenoma }\end{array}$ & $\begin{array}{c}\text { Size } A P \times C C \\
(\mathrm{~mm})\end{array}$ & T1WI & $\mathrm{T} 2 \mathrm{WI}$ & Enhancement & $\begin{array}{l}\text { Resolution } \\
\text { on Follow-Up }\end{array}$ & $\begin{array}{l}\text { Surgical } \\
\text { Treatment }\end{array}$ & Ophthalmoplegia \\
\hline 1 & 23 & $\mathrm{~F}$ & No & $1.9 \times 15.2$ & Iso & NA & Yes & NA & No & No \\
\hline 2 & 57 & $\mathrm{M}$ & No & $4.3 \times 39.2$ & Iso & NA & No & Yes & Yes & Yes \\
\hline 3 & 42 & $\mathrm{M}$ & No & $4.7 \times 30.4$ & Iso & Нypo & Yes & NA & No & Yes \\
\hline 4 & 53 & $\mathrm{M}$ & Yes & $6.3 \times 47.9$ & Iso & Hyper & Yes & Yes & Yes & Yes \\
\hline 5 & 81 & $\mathrm{M}$ & No & $4.5 \times 45.7$ & Iso & Hypo & Yes & Yes & Yes & Yes \\
\hline 6 & 37 & $\mathrm{M}$ & No & $3.6 \times 26.7$ & Iso & NA & Yes & NA & Yes & Yes \\
\hline 7 & 82 & $\mathrm{~F}$ & No & $2.7 \times 12.2$ & Iso & NA & Yes & No & Yes & Yes \\
\hline 8 & 67 & $\mathrm{M}$ & No & $2.2 \times 19.9$ & Iso & NA & Yes & Yes & Yes & Yes \\
\hline 9 & 55 & M & No & $2.4 \times 27.6$ & Iso & Нypo & Yes & Yes & Yes & Yes \\
\hline 10 & 70 & M & No & $3.8 \times 39.6$ & Iso & NA & Yes & NA & Yes & Yes \\
\hline
\end{tabular}

$\mathrm{AP}=$ anteroposterior; $\mathrm{CC}=$ craniocaudal; hyper = hyperintense; hypo = hypointense; iso = isointense; $\mathrm{NA}=$ not applicable; $\mathrm{T} 1 \mathrm{WI}=\mathrm{T} 1$-weighted imaging; $\mathrm{T} 2 \mathrm{WI}=\mathrm{T} 2$-weighted imaging. 

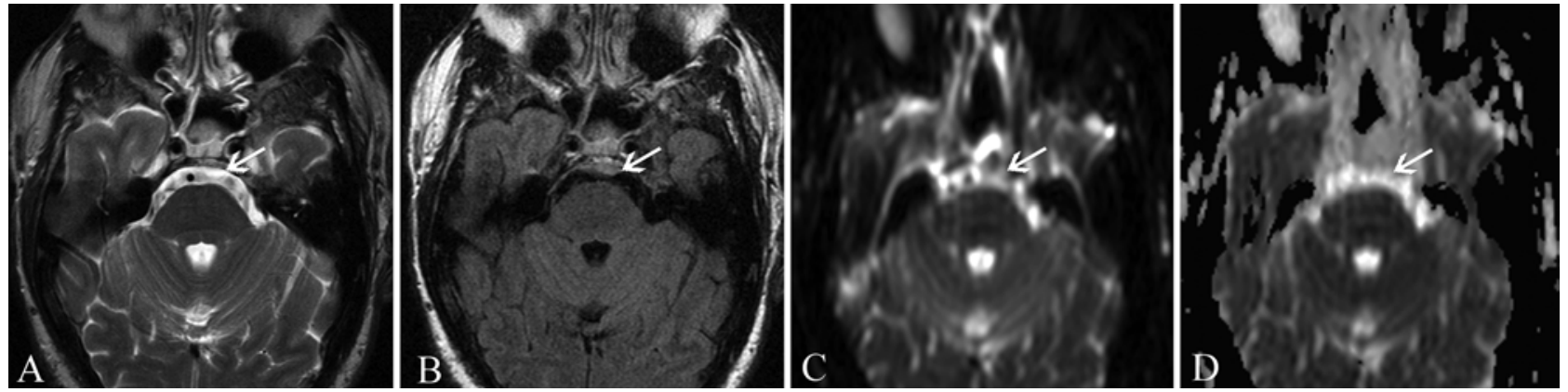

FIG. 2. Case 4. Axial FLAIR (A), T2-weighted MR image (B), apparent diffusion coefficient map (C), and diffusion-weighted image (D) obtained at the level of the clivus. A: A hyperintense mass is seen posterior to the clivus, which is indented by the basilar artery. B: There is no appreciable narrowing of the artery or loss of flow void. The signal characteristics are hyperintense to cerebrospinal fluid, which was unique to this patient. $\mathbf{C}$ and $\mathbf{D}$ : The apparent diffusion coefficient map and diffusion-weighted image do not show evidence of diffusion restriction.

our knowledge, 27 case reports of retroclival hemorrhage exist in the literature, and only 2 have been attributed to pituitary apoplexy. In this current series of 18 patients, 10 were found to have retroclival hemorrhage. This is the first study to systematically review a series of apoplexy patients. Some of the hemorrhages in this study were subtle and not identified at the time the MRI was initially read. In other cases, the hemorrhages were large and easily diagnosed. Based on our findings, it is likely that small hemorrhages occur in nearly half of the cases of apoplexy, but are typically ignored for being too subtle. It is important to note that even the large hemorrhages in this series did not require surgical intervention since there were no clinical signs of mass effect on the posterior fossa contents.

The vast majority of cases of pituitary apoplexy occur in the setting of a preexisting pituitary adenoma. In approximately $83 \%$ of cases, the adenoma is undiagnosed at the time of presentation..$^{15,16}$ Ninety percent of the patients in this series had undiagnosed pituitary adenomas. The majority of adenomas that undergo apoplexy are nonfunctioning macroadenomas. ${ }^{17}$ It is hypothesized that nonfunctioning adenomas are more likely to hemorrhage because they go undetected longer than functioning adenomas and, as a result, are larger at the time of presentation. There is a slight sex predominance toward males (60\%), and the average age in surgical series is 50 years. ${ }^{6-11,15,16}$ Arita et al. found that over a 5-year follow-up period, pituitary apo-
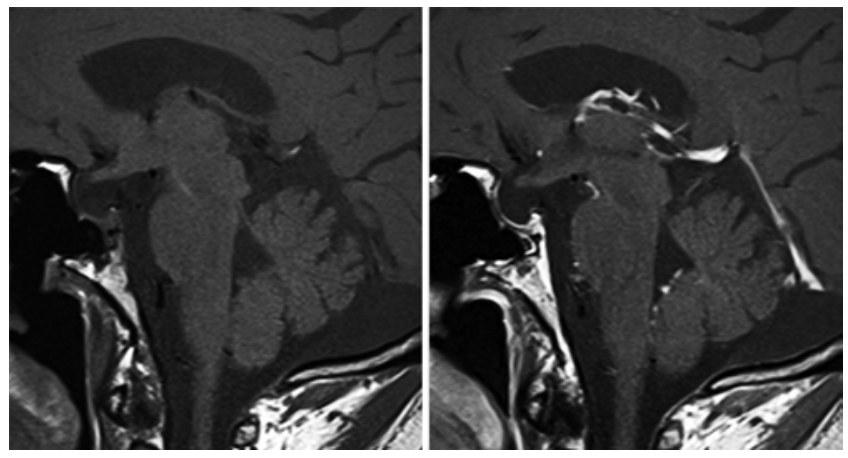

FIG. 3. Sagittal precontrast (left) and postcontrast (right) T1-weighted MRI sequences of the sella turcica obtained in the same patient in Fig. 1. Three months after the initial symptoms of pituitary apoplexy, complete resolution of the retroclival enhancing hematoma was observed. plexy developed in $9.5 \%$ of patients with known pituitary adenoma. ${ }^{1}$

Sudden onset of headache is present in approximately $89 \%$ of cases and nausea in $57 \%$ of cases. Fifty percent of patients also experience various forms of ophthalmoplegia, including diminished visual acuity, visual field defects, or diplopia. ${ }^{6-14}$ In our series, all patients reported experiencing headache, and all but 1 patient had ophthalmoplegia of some kind. The recommended management-either conservative medical treatment ${ }^{19}$ or surgical decompression ${ }^{4,19}$-remains controversial depending on the presence of associated cranial nerve palsies and level of consciousness. Typically, the presence of ophthalmoplegia is the determining factor for determining which patients receive transsphenoidal surgical decompression.

The presence of retroclival hemorrhage within a specific compartment cannot be accurately determined based solely on the imaging appearance. Traditionally, an epidural location has been inferred; however, the dura mater overlying the clivus is unique in that it is composed of a 2-layered structure that contains the basilar venous plexus. ${ }^{2,9,16}$ Thus, the term "interdural" has been suggested to describe this anatomical location..$^{15,16}$ The convex appearance of the retroclival hemorrhage in our series is suggestive of a subdural location, in which blood is located between the dura mater and the anterior prepontine membrane., ${ }^{2,12,15}$ In several cases included in this series, a linear enhancing structure was present along the clivus that was separate from the hemorrhage, and likely represented the dura. In addition, the anatomical location of these hemorrhages may account for the complete resolution in the majority $(83 \%)$ of the patients on follow-up imaging, due to the rich superior and inferior petrosal venous network that communicates with the subdural space. ${ }^{2,8}$

The major differential consideration for retroclival hemorrhage is engorgement of the basilar venous plexus. Although mild enhancement within the hemorrhages was seen, it did not extend to the adjacent venous structures, thereby making the cases in this series unlikely to represent venous plexus engorgement. In multiple patients, there was a clear elevation of the dura that extended from the clivus and was continuous with the diaphragma sella. Therefore, the most likely pathophysiology for the hemorrhage was direct extension from the sella. 


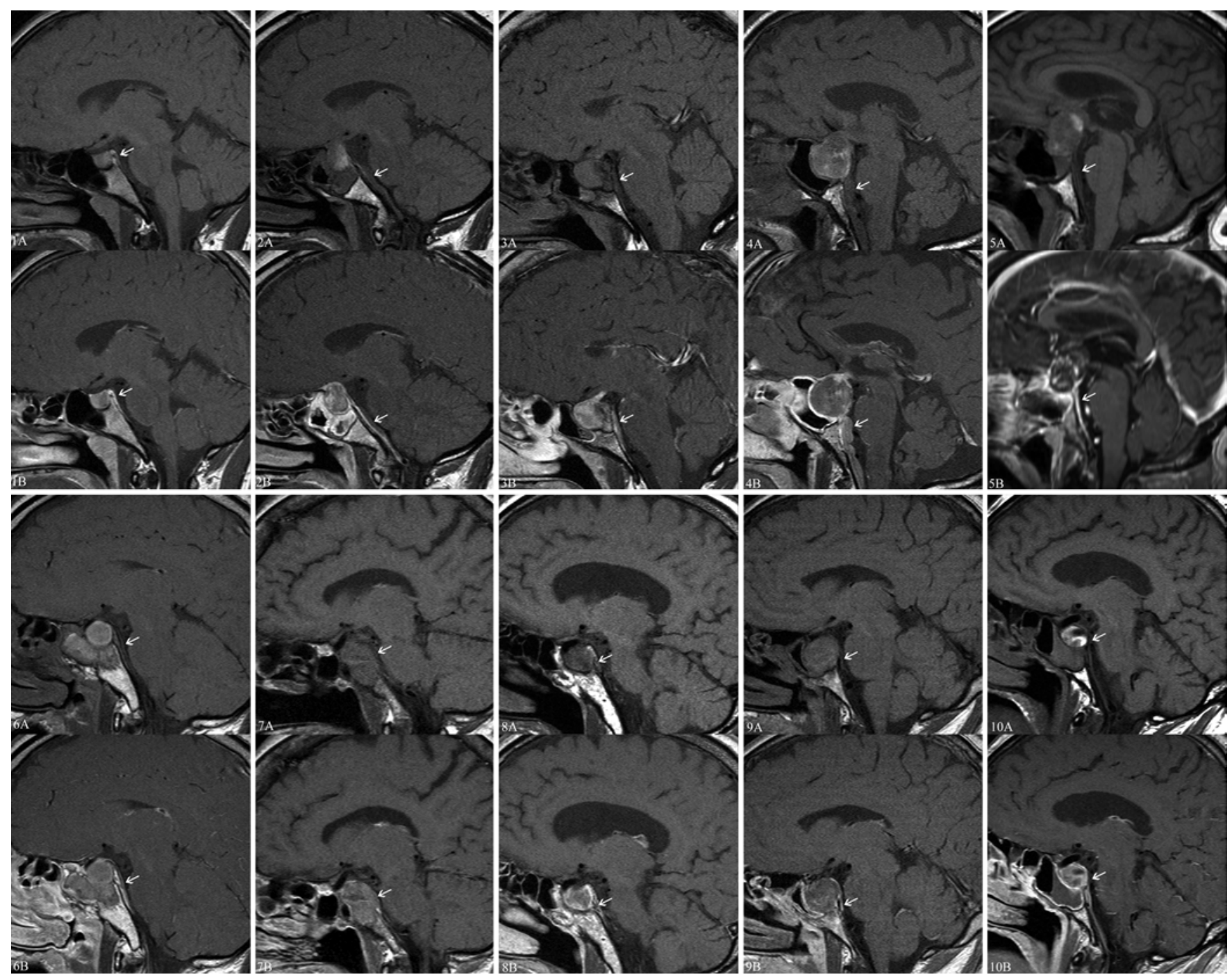

FIG. 4. Sagittal T1-weighted precontrast (upper) and postcontrast (lower) images for all 10 patients with identified retroclival hemorrhage are provided.

The differential diagnosis for a retroclival hemorrhage is relatively short and straightforward. Retroclival hemorrhage most commonly occurs in the setting of trauma, in which injury to the skull base or cervicocranial injury is to be expected. Diagnosing retroclival hemorrhage in association with pituitary apoplexy is greatly aided by the unique appearance of apoplexy. A retroclival abscess may have imaging findings similar to subacute hemorrhage; however, the clinical settings for each are different. Diseases that thicken the meninges, such as carcinomatosis or granulomatous disease, may mimic focal hemorrhage, but the distributions of these are much more diffuse and would rarely be isolated to the retroclival meninges. Finally, intracranial hypotension due to cerebrospinal fluid leakage can cause engorgement of the retroclival plexus, mimicking hemorrhage. In such cases, other intracranial signs of hypotension, such as venous sinus engorgement and pachymeningeal enhancement, are typically present and can be used to aid diagnosis.

\section{Conclusions}

Pituitary apoplexy is rare, but the majority of cases presented here (10 of 18 patients) appear to be associated with retroclival hemorrhage, thereby suggesting that retroclival hemorrhage maybe more common than previously thought.

\section{References}

1. Arita K, Tominaga A, Sugiyama K, Eguchi K, Iida K, Sumida M, et al: Natural course of incidentally found nonfunctioning pituitary adenoma, with special reference to pituitary apoplexy during follow-up examination. J Neurosurg 104:884-891, 2006

2. Ayberk G, Ozveren MF, Aslan S, Yaman ME, Yaman O, Kayaci S, et al: Subarachnoid, subdural and interdural spaces at the clival region: an anatomical study. Turk Neurosurg 21:372-377, 2011

3. Brock S, Prada F, Maccagnano E, Giombini S: Interdural haemorrhage of the posterior fossa due to infraclinoidal 
carotid artery aneurysm rupture. Acta Neurochir (Wien) 152: 1543-1546, 2010

4. Chanson P, Lepeintre JF, Ducreux D: Management of pituitary apoplexy. Expert Opin Pharmacother 5:1287-1298, 2004

5. Cho CB, Park HK, Chough CK, Lee KJ: Spontaneous bilateral supratentorial subdural and retroclival extradural hematomas in association with cervical epidural venous engorgement. J Korean Neurosurg Soc 46:172-175, 2009

6. Famini P, Maya MM, Melmed S: Pituitary magnetic resonance imaging for sellar and parasellar masses: ten-year experience in 2598 patients. J Clin Endocrinol Metab 96:1633-1641, 2011

7. Goodman JM, Kuzma B, Britt P: Retroclival hematoma secondary to pituitary apoplexy. Surg Neurol 47:79-80, 1997

8. Huang YP, Wolf BS, Antin SP, Okudera T: The veins of the posterior fossa-anterior or petrosal draining group. Am J Roentgenol Radium Ther Nucl Med 104:36-56, 1968

9. Kawase T, van Loveren H, Keller JT, Tew JM: Meningeal architecture of the cavernous sinus: clinical and surgical implications. Neurosurgery 39:527-536, 1996

10. Khan N, Zumstein B: Transverse clivus fracture: case presentation and significance of clinico-anatomic correlations. Surg Neurol 54:171-177, 2000

11. Kim MS, Jung JR, Yoon SW, Lee CH: Subdural hematoma of the posterior fossa due to posterior communicating artery aneurysm rupture. Surg Neurol Int 3:39, 2012

12. Matsuno H, Rhoton AL Jr, Peace D: Microsurgical anatomy of the posterior fossa cisterns. Neurosurgery 23:58-80, 1988

13. Mizushima H, Kobayashi N, Sawabe Y, Hanakawa K, Jinbo $\mathrm{H}$, Iida M, et al: Epidural hematoma of the clivus. Case report. J Neurosurg 88:590-593, 1998

14. Mohamed AH, Rodrigues JC, Bradley MD, Nelson RJ: Retroclival subdural haematoma secondary to pituitary apoplexy. Br J Neurosurg 27:845-846, 2013

15. Ozveren MF, Ayberk G, Kayaci S: Are traumatic rectroclival hematomas located epidurally, interdurally, or subdurally? Neurosurgery 69:E1185-E1186, 2011 (Letter)
16. Ozveren MF, Uchida K, Aiso S, Kawase T: Meningovenous structures of the petroclival region: clinical importance for surgery and intravascular surgery. Neurosurgery 50:829837,2002

17. Paterakis KN, Karantanas AH, Hadjigeorgiou GM, Anagnostopoulos V, Karavelis A: Retroclival epidural hematoma secondary to a longitudinal clivus fracture. Clin Neurol Neurosurg 108:67-72, 2005

18. Schievink WI, Thompson RC, Loh CT, Maya MM: Spontaneous retroclival hematoma presenting as a thunderclap headache. Case report. J Neurosurg 95:522-524, 2001

19. Sibal L, Ball SG, Connolly V, James RA, Kane P, Kelly WF, et al: Pituitary apoplexy: a review of clinical presentation, management and outcome in 45 cases. Pituitary 7:157-163, 2004

20. Tomaras C, Horowitz BL, Harper RL: Spontaneous clivus hematoma: case report and literature review. Neurosurgery 37:123-124, 1995

21. Tubbs RS, Griessenauer CJ, Hankinson T, Rozzelle C, Wellons JC III, Blount JP, et al: Retroclival epidural hematomas: a clinical series. Neurosurgery 67:404-407, 2010

\section{Author Contributions}

Conception and design: Azzam, Maya. Acquisition of data: Azizyan, Azzam, Maya, Famini, Pressman. Analysis and interpretation of data: Azizyan, Azzam, Maya. Drafting the article: Azzam, Maya. Critically revising the article: Azizyan, Moser. Reviewed submitted version of the manuscript: Azizyan, Miller, Moser. Approved the final version of the manuscript on behalf of all authors: Azizyan. Statistical analysis: Azizyan, Azzam, Maya. Administrative/technical/material support: Miller, Maya, Pressman.

\section{Correspondence}

Avetis Azizyan, S. Mark Taper Foundation Imaging Center, Cedars-Sinai Medical Center, 8700 Beverly Blvd., Ste. M-335, Los Angeles, CA 90048. email: aazizyan@gmail.com. 